\title{
Isolation and Structural Studies on Chemical Constituents from Catharanthus roseus Leaf Ethyl Acetate Extract
}

Shahin Aziz ${ }^{*}$, Koushik Saha ${ }^{2}$

${ }^{1}$ Chemical Research Division, BCSIR Laboratories Dhaka, Bangladesh Council of Scientific and Industrial Research, Dhamondi, Dhaka-1205,

Bangladesh

${ }^{2}$ Department of Chemistry, Jahangirnagar University, Savar, Dhaka-1342, Bangladesh

DOI: $\underline{10.36347 / \mathrm{sajb} .2020 . v 08 i 12.001}$

| Received: 26.11.2020 | Accepted: 09.12.2020 | Published: 13.12.2020

*Corresponding author: Dr. Shahin Aziz

Abstract

Original Research Article

Catharanthus roseus is an important medicinal plant in Bangladesh. The plant is administered as a cooling medicine. From Ethyl Acetate (EA) extract Compounds: oleanolic acid (1), betullinic acid (2), ursolic acid (3) \& myricitin (4) have been isolated from leaf part of this plant. The structures of the compounds have been established by different spectroscopic data analysis. From leaf EA extract compounds betullinic acid and myricitin were isolated for the first time from this plant.

Keywords: Catharanthus roseus, isolation, structure elucidation, spectroscopic methods.

Copyright ( 12020 The Author(s): This is an open-access article distributed under the terms of the Creative Commons Attribution 4.0 International License (CC BY-NC 4.0) which permits unrestricted use, distribution, and reproduction in any medium for non-commercial use provided the original author and source are credited.

\section{INTRODUCTION}

Nature has bestowed on us a very rich botanical wealth and a large number of diverse types of plants grown in different parts of the country [1]. Today, according to world health organization (WHO) as many as $80 \%$ of the world's people depend on traditional medicine for their primary health care needs [2]. High plants are sources of drug which have made important contribution to the welfare and quality of life urban as well as rural communities especially in tropics and sub-tropics [3]. During the early years of human existence, many plants materials by instinct, intuition of trial and error were used to combat different aliments [4].

Catharanthus roseus, as a medicinal plants (Common name - Periwinkle, Vinca; Bengali Nayantara, Synonyms - Vinca rosea; Family Apocyanaceae) popularly known as madagascar periwinkle is a potential source for anti-leukemic alkaloids. It is cultivated mainly for its alkaloids which are having anticancer activities [5]. It is an evergreen subshrub or harbeceous plant growing up to $1 \mathrm{~m}$ tall [6]. This plant is administered as a cooling medicine. It is used for the treatment of diabetes, fever, malaria, throat infection and chest complaints. It is also used for the regulation of menstrual cycles, and as a euphoriant [7]. The plant is an important source of indole alkaloids which are present in all plant parts. The physically important and antineoplastic alkaloids namely Vincristine and Vinblastine are mainly present in the leaves whereas antihypertensive alkaloids such as ajmalicine, serpentine and reserpine are reported to be present in the roots [8]. Vincristine and Vinblastine alkaloids are used in the treatment of various types of lymphoma and leukemia [9, 10]. These Catharanthus alkaloids are also used for the treatment of both malignant and nonmalignant diseases and in platelet and platelet associated disorder. Previous phytochemical investigations resulted in the isolation of Kaemferol [11], Kaempferol trisaccarides [12], Quercetin [13], Quercetin trisaccarides [11], Syringetin glycosides [14], Malvidin [13], Malvidin 3-0-glucosides [15], Malvidin 3-0-(6-0-p-coumaroyl) [15], Petunidin [13], Petunidin 3-0-glucosides [15], Petunidin 3-0-(6-0-p-coumaroyl) [15], Hirsutidin [13], Hirsutidin 3-0-glucosides [15], Hirsutidin 3-0-(6-0-p-coumaroyl) [15]. Catharanthus Plant produce many pharmaceutically important alkaloids. They are antineoplastic medicines and the monoindole alkaloids ajmalicin and serpentine are antihypertension drugs [16-22], Our recent study on EA extract of leaf of this plant has led to the isolation of oleanolic acid (1), betullinic acid (2), ursolic acid (3) \& myricitin (4) (Figure-1). Compounds betullinic acid and myricitin were isolated from leaf EA extract for the first time from this plant. 


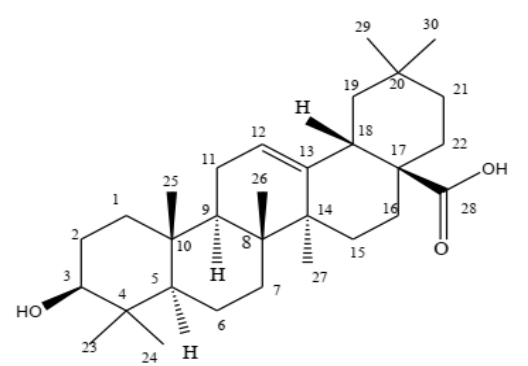

3ß-Hydroxy-12-oleanen-28-oic acid or

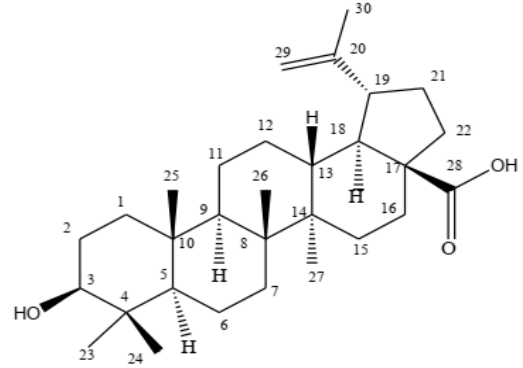

3及-Hydroxy-lup-20 (29)-en-28-oic acid or
Oleanolic acid (1)

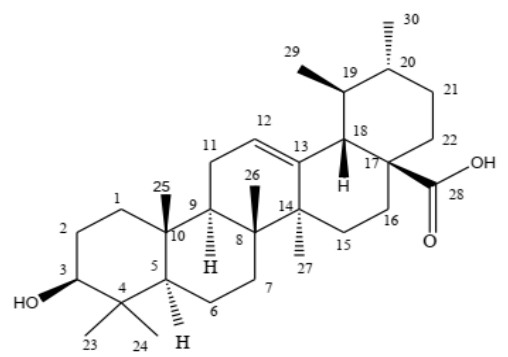

Ursolic acid (3)
Betulinic acid (2)<smiles>O=c1c(O)c(-c2cccc(O)c2)oc2cc(O)c(O)c(O)c12</smiles>

3,3',4',5,5',7-hexahydroxy flavone or Myricetin (4)

Fig-1: Structures of the isolated compounds with numbering

\section{MATERIALS AND METHODS}

Melting points were determined by thin disc method on a Fisher-John's electrothermal melting point apparatus. UV spectra were recorded in methanol on a Shimadzu UV-Visible spectrophotometer. IR spectra were recorded on a Shimadzu FT-IR spectrometer as thin film or $\mathrm{KBr}$ disc. NMR spectra were recorded in $\mathrm{CDCl}_{3}$ and $\mathrm{CD}_{3} \mathrm{OD}$ using Bruker $\mathrm{WH} 400 \mathrm{MHz}$ NMR spectrometer. Mass spectra of the compounds were measured on Finnigan Mat SSQ 710 spectrometer with ionization induced by electron impact at $70 \mathrm{eV}$. Separation by column chromatography was carried out using silica gel 40 (70-230 mesh, E. Merck). Thin layer chromatography was carried out on TLC plastic sheets pre-coated with silica gel $60 \mathrm{~F}_{254}$ (E. Merck).

\section{Collection of Plant Material}

Fully matured fresh leaves of this plant were collected from the gardens of Chemistry Department of Dhaka university, Bangladesh in June 2013 and identified by the taxonomist of Bangladesh national Herbarium, Dhaka, where a voucher specimen (No. = 39512) has been deposited. The leaves C. roseus were air dried. These dried samples of leaves were powdered using 20 mesh screen in Willey mill and then used for subsequent analysis. and

\section{Extraction of the leaf parts of $C$. roseus}

The dried, screened leaf powder $(510 \mathrm{~g})$ was extracted with methanol at room temperature for 5 days. The filtrate was dried into a gummy mass using rotary evaporator under reduced pressure. The methanol extract $(40.0 \mathrm{~g})$ was then triturated by $\mathrm{n}$-hexane $(100 \mathrm{ml} \times 3)$, then by ethyl acetate $(100 \mathrm{ml} \times 3)$. Then these extracts were dried by using a rotary evaporator to get ethyl acetate extract $(9.0 \mathrm{~g})$.

\section{Isolation of compounds from crude extracts}

The ethyl acetate extract of leaf part $(4.0 \mathrm{~g})$ was dissolved in minimum amount of same solvents and adsorbed by the column grade silica gel. The adsorbed sample was placed on the top of the silica gel bed (TLC grade) packed in VLC apparatus and was first eluted with $100 \%$ n-hexane. It was then eluted with mixtures of n-hexane and ethyl acetate (EA) and finally with the mixtures of ethyl acetate and methanol with increasing polarity. Twenty six collections of $200 \mathrm{ml}$ each were collected and combined into six fractions according to their TLC behaviors.

Depending on the TLC behavior, VLC fraction 2 (collection no.4-6), 3 (collection no. 7-8) and 4 (collection no. 9-15) were selected for further investigation for further investigation to the isolation of the compounds (1), (2), (3), (4).The VLC fraction 2 (collection no. 4-6, $112 \mathrm{mg}$ ) of the ethyl acetate extract was kept in solvent at room temperature for three days and colorless crystals were separated out. The crystals were separated by decantation process and washed with few drops of chloroform to get the compound (1) (11.3 $\mathrm{mg}$ ) in pure form. The VLC fraction 3 (collection no. $7-8,0.95 \mathrm{~g}$ ) was subjected to a medium sized silica gel 
column made by $100 \% \mathrm{n}$-hexane for further separation. The column was eluted with n-hexane, n-hexane-DCM and DCM-methanol in gradient manner. Compound (2) $(4.45 \mathrm{mg})$ was isolated as crystals from the collection no. 15-18 (10 ml each) after evaporation of the solvent mixture. The compound (3) (9.3 mg) was also isolated in pure form as crystals from later collections (collection no. 32-36) of the same column with the similar procedure. Both the compounds were found as TLC pure and were soluble in chloroform mixed with few drops of methanol.

The VLC fraction 4 (collection no. 9-15, 110 $\mathrm{mg}$ ) was subjected to column chromatography to separate the compound (4). The column was made by silica get in $50 \% \mathrm{CHCl}_{3}$ in n-hexane was eluted with n-hexane-chloroform and chloroform-methanol solvent systems with increasing polarity. The compound was collected as almost in pure form from the collection no. 20-25 (10 ml each) of the column. The compound (4) (7.6 mg) was finally purified as yellow crystals by re-crystallization from minimum amount of ethyl acetate. The crystals were completely soluble in methanol.

\section{Spectroscopic data of the isolated compounds Compound (1)}

Colorless crystals; mp $305-307^{\circ} \mathrm{C}$; IR (neat) v 3421 (O-H), 2965, 2872, 1688 (C=O), 1457, 1214, 1031 $(\mathrm{C}-\mathrm{O}) \mathrm{cm}^{-1} ;{ }^{1} \mathrm{H} \mathrm{NMR}\left(\mathrm{CDCl}_{3}+\mathrm{CD}_{3} \mathrm{OD}\right) \delta 5.16(1 \mathrm{H}$, unr. s, H-12), 3.12 (1H, t, J=7.2 Hz, H-3), 2.56 (1H, unr. s), $2.11(2 \mathrm{H}, \mathrm{m}), 1.78-1.92(3 \mathrm{H}, \mathrm{m}), 1.38-1.61(10 \mathrm{H}, \mathrm{m})$, 1.20-1.35 (8H, m), $1.18(3 \mathrm{H}, \mathrm{s}), 1.00(3 \mathrm{H}, \mathrm{s}), 0.90(3 \mathrm{H}$, s), $0.87(3 \mathrm{H}, \mathrm{s}), 0.85(3 \mathrm{H}, \mathrm{s}), 0.73(3 \mathrm{H}, \mathrm{s}), 0.69(3 \mathrm{H}, \mathrm{s})$; ${ }^{13} \mathrm{C}$ NMR $\left(\mathrm{CDCl}_{3}+\mathrm{CD}_{3} \mathrm{OD}\right) \delta 180.6(\mathrm{C}-28), 138.1$ (C-13), 125.4 (C-12), 78.8 (C-3), 55.2, 52.7, 47.7, 47.5, 42.0, 39.4, 39.0, 38.8, 38.7, 38.6, 36.9, 36.7, 33.0, 30.6, 28.9, 28.0, 26.8, 24.1, 23.4, 23.2, 21.0, 18.2, 16.9, 16.8, 15.5, 15.3; MS m/z $456\left(\mathrm{M}^{+}\right), 248$ (base peak), 203, 189, $175,133,119,105,95,81,57,43$.

\section{Compound (2)}

White crystals; m. p. 314-316 C; IR (neat) v 3375 (O-H), 2839, 1642 (C=O), 1410, 1235, 1106 (C-O) $\mathrm{cm}^{-1}$; ${ }^{1} \mathrm{H} \mathrm{NMR}\left(\mathrm{CDCl}_{3}+\mathrm{CD}_{3} \mathrm{OD}\right) \delta 4.65(1 \mathrm{H}$, unr. s, $\left.\mathrm{H}_{\mathrm{a}}-29\right)$, 4.52 (1H, unr. s, $\left.\mathrm{H}_{\mathrm{b}}-29\right), 3.32$ (1H, unr. S, H-3), $2.15(3 \mathrm{H}, \mathrm{t}, J=12.0 \mathrm{~Hz}), 1.82-1.92(3 \mathrm{H}, \mathrm{m}), 1.61(3 \mathrm{H}, \mathrm{s}$, $\mathrm{H}-30), 1.39-1.58(7 \mathrm{H}, \mathrm{m}), 1.24-1.38$ (8H, m), 1.05-1.23 $(5 \mathrm{H}, \mathrm{m}), 0.89(3 \mathrm{H}, \mathrm{s}), 0.88(3 \mathrm{H}, \mathrm{s}), 0.86(3 \mathrm{H}, \mathrm{s}), 0.74$ $(3 \mathrm{H}, \mathrm{s}), 0.67(3 \mathrm{H}, \mathrm{s}) ;{ }^{13} \mathrm{C} \mathrm{NMR}\left(\mathrm{CDCl}_{3}+\mathrm{CD}_{3} \mathrm{OD}\right) \delta$ $179.1(\mathrm{C}=\mathrm{O}), 150.7$ (C-20), 109.4 (C-29), 78.8 (C-3), 56.1, 55.3, 50.5, 49.1, 46.9, 42.4, 40.6, 38.8, 38.7, 38.2, 37.1 (2C), 34.2, 32.2, 30.5, 29.6, 27.8, 27.0, 25.5, 20.8, 19.2, 18.2, 16.0, 15.8, 15.3, 14.6; MS m/z $456\left(\mathrm{M}^{+}\right), 438$, $423,395,207,189,175,135,119,107,95,81,69,43$ (basepeak).

\section{Compound (3)}

White crystals; m. p. $283-285^{\circ} \mathrm{C}$; IR (neat) v 3421 (O-H), 2925, 2871, 1687 (C=O), 1456, 1376' 1284, $1171(\mathrm{C}-\mathrm{O}) \mathrm{cm}^{-1} ;{ }^{1} \mathrm{H}$ NMR $\left(\mathrm{CDCl}_{3}+\mathrm{CD}_{3} \mathrm{OD}\right) \delta 5.12$ (1H, unr. s, H-12), 3.08 (1H, t, J=7.2 Hz, H-3), $2.07(1 \mathrm{H}$, d, $J=11.2 \mathrm{~Hz}), 1.72-1.93(5 \mathrm{H}, \mathrm{m}), 1.32-1.65(13 \mathrm{H}, \mathrm{m})$, 1.15-1.30 (5H, m), $0.97(3 \mathrm{H}, \mathrm{s}), 0.86(3 \mathrm{H}, \mathrm{s}), 0.83(3 \mathrm{H}, \mathrm{d}$, $J=6.0 \mathrm{~Hz}, \mathrm{H}-29$ or H-30), $0.80(3 \mathrm{H}, \mathrm{s}), 0.75(3 \mathrm{H}, \mathrm{d}, J=6.4$ $\mathrm{Hz}, \mathrm{H}-29$ or H-30), 0.69 (3H, s), 0.66 (3H, s); ${ }^{13} \mathrm{C}$ NMR $\left(\mathrm{CDCl}_{3}+\mathrm{CD}_{3} \mathrm{OD}\right) \delta 180.7(\mathrm{C}-28), 138.1(\mathrm{C}-13), 125.4$ (C-12), 78.8 (C-3), 55.1, 52.7, 47.7, 47.4, 41.9, 39.3, 39.0, 38.8, 38.6 (2C), 36.8, 36.7, 32.9, 30.5, 27.9 (2C), 26.3, 24.1, 23.4, 23.1, 21.0, 18.2, 16.9, 16.7, 15.5, 15.3; MS m/z $456\left(\mathrm{M}^{+}\right), 438,248$ (base peak), 203, 189, 133, $119,105,95,81,57,43$.

\section{Compound (4)}

Yellow crystals; mp 354-356 C; UV $\left(\mathrm{CH}_{3} \mathrm{OH}\right)$ $\lambda_{\max } 379,320,303 \mathrm{~nm}$; IR (neat) v 3365 (br., O-H), 1659 $(\mathrm{C}=\mathrm{O}), 1611,1205,1166(\mathrm{C}-\mathrm{O}) \mathrm{cm}^{-1} ;{ }^{1} \mathrm{H} \mathrm{NMR}\left(\mathrm{CD}_{3} \mathrm{OD}\right)$ $\delta 7.33\left(2 \mathrm{H}, \mathrm{s}, \mathrm{H}-2^{\prime} \& \mathrm{H}-6\right), 6.36(1 \mathrm{H}, \mathrm{d}, J=2.0 \mathrm{~Hz}, \mathrm{H}-6)$, $6.17(1 \mathrm{H}, \mathrm{d}, J=2.0 \mathrm{~Hz}, \mathrm{H}-8) ;{ }^{13} \mathrm{C}$ NMR $\left(\mathrm{CD}_{3} \mathrm{OD}\right) \delta 177.3$ $(\mathrm{C}=\mathrm{O}), 165.5,162.5,158.2,148.0,146.7$ (C-3' \& C-5), 137.3, 136.9, 123.1, 108.5 (C-2' \& C-6), 104.5, 99.2, 94.3; MS m/z $318\left(\mathrm{M}^{+}\right), 302,289,198,153,136,95$.

\section{RESULTS AND DISCUSSION}

EA extract of leaf of this plant has yielded to the isolation of oleanolic acid (1), betullinic acid (2), ursolic acid (3) \& myricitin (4) (Figure-1). The compound (1) (11.3 mg) was found as colorless crystal and was completely soluble in the mixture of chloroform and methanol. Melting point of the compound was found as $305-307^{\circ} \mathrm{C}$. It showed single spot on TLC plate with $\mathrm{R}_{\mathrm{f}}$ value 0.53 in $40 \%$ ethyl acetate in $n$-hexane.

The mass spectrum of the compound showed a molecular ion peak at $\mathrm{m} / \mathrm{z} 456$ corresponding to the molecular formula $\mathrm{C}_{30} \mathrm{H}_{48} \mathrm{O}_{3}$. The IR spectrum of the compound (1) showed absorption band at $3421 \mathrm{~cm}^{-1}$ due to the $\mathrm{O}-\mathrm{H}$ stretching vibration. It was also supported by the absorption bands at 1214 and $1031 \mathrm{~cm}^{-1}$ due to the $\mathrm{C}-\mathrm{O}$ stretching vibrations. The sharp absorption bands at 2965 and $2872 \mathrm{~cm}^{-1}$ for saturated $\mathrm{C}-\mathrm{H}$ stretching vibrations and band at $1457 \mathrm{~cm}^{-1}$ due to $\mathrm{C}-\mathrm{H}$ bending vibrations, respectively. The presence of carbonyl group was indicated by the absorption band found at $1688 \mathrm{~cm}^{-1}$. In the ${ }^{1} \mathrm{H}$ NMR spectrum, the unresolved singlet at $\delta 5.16$ clearly indicated the presence of an olefinic proton attached to $\mathrm{C}-12$ which was supported by peaks at $\delta$ $125.4 \& 138.1$ in the ${ }^{13} \mathrm{C}$ NMR spectrum. The one proton triplet at $\delta 3.12$ indicated the presence of methine proton at $\mathrm{C}-3$ attached to the hydroxyl group. This was further supported by the ${ }^{13} \mathrm{C}$ NMR signal at $\delta 78.8$. The presence of seven methyl groups in the structure was clearly showed by the seven singlets integrated by three protons each at $\delta 1.18,1.00,0.90,0.87,0.85,0.73 \& 0.69$ in the ${ }^{1} \mathrm{H}$ NMR spectrum. 
The ${ }^{13} \mathrm{C}$ NMR spectrum indicated the presence of total 30 carbons in the molecule by 30 peaks. The signal at $\delta 180.6$ indicated the carbon of carboxyl group at position 28. All the spectral data analysis and the molecular formula of the compound suggested that the compound (1) is a pentacyclic triterpenoid containing one hydroxyl group, one double bond and a carboxyl group. In the mass spectrum, the ion from retro-Diels-Alder cleavage at $\mathrm{m} / \mathrm{z} 248$ (base peak) and its fragment ion at $\mathrm{m} / \mathrm{z} 203$ [248-45(-COOH)] was very much consistent with the following structure of the compound.

Based on all spectroscopic data, literature values [23] and melting point of the compound (1), it was confirmed that compound is $3 \beta$-Hydroxy-12-oleanen-28-oic acid or Oleanolic acid. The structure of the compound (1) is given below:

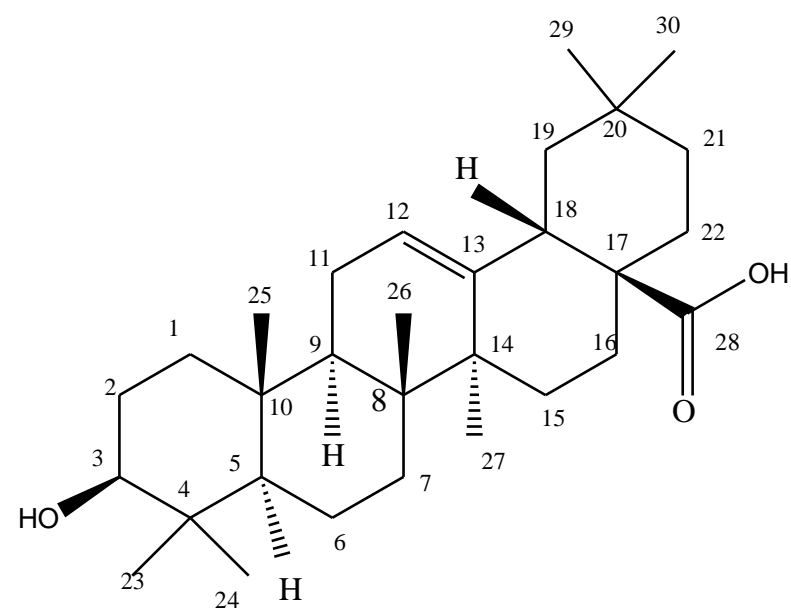

3及-Hydroxy-12-oleanen-28-oic acid or Oleanolic acid (1)

The compound (2) (4.4 mg) was found as white crystal and was completely soluble in the mixture of chloroform and methanol. Melting point of the compound was found as $314-316^{\circ} \mathrm{C}$. It showed single spot on TLC plate with $\mathrm{R}_{\mathrm{f}}$ value 0.55 in $50 \%$ ethyl acetate in $n$-hexane.

The mass spectrum of the compound showed a molecular ion peak at $\mathrm{m} / \mathrm{z} 456$ which is corresponding to the molecular formula $\mathrm{C}_{30} \mathrm{H}_{48} \mathrm{O}_{3}$. The IR spectrum of the compound (2) showed absorption band at $3375 \mathrm{~cm}^{-1}$ due to the $\mathrm{O}-\mathrm{H}$ stretching vibration. It is also supported by the absorption bands at 1235 and $1106 \mathrm{~cm}^{-1}$ due to the $\mathrm{C}-\mathrm{O}$ stretching vibrations. The sharp absorption band at $2839 \mathrm{~cm}^{-1}$ is due to saturated $\mathrm{C}-\mathrm{H}$ stretching vibrations and band at $1410 \mathrm{~cm}^{-1}$ due to $\mathrm{C}-\mathrm{H}$ bending vibrations, respectively. The presence $\mathrm{C}=\mathrm{O}$ of carboxyl group was indicated by the absorption band found at $1642 \mathrm{~cm}^{1}$.

The two unresolved singlets at $\delta 4.65 \& 4.52$ integrated for one proton each in the ${ }^{1} \mathrm{H}$ NMR spectrum indicated the two olefinic protons attached to C-29. Another unresolved singlet at $\delta 3.32(1 \mathrm{H})$ showed the presence of $>\mathrm{CHOH}$ group in the molecule. The presence of six methyl groups in the structure was confirmed by the six three-proton singlets at $\delta 1.61,0.89$, $0.88,0.86,0.74 \& 0.67$.

The ${ }^{13} \mathrm{C}$ NMR spectrum showed 29 signals for 30 carbons. The signal at $\delta 37.1$ represented for two carbons and the signal at $\delta 49.1$ overlapped with solvent $\left(\mathrm{CD}_{3} \mathrm{OD}\right)$ peaks which was clearly indicated in the DEPT spectrum. The two peaks at $\delta 150.7 \& 109.4$ indicated the presence of two olefinic carbons at C-20 \& $\mathrm{C}-29$ and the peak at $\delta 78.8$ represented the $\mathrm{C}-3$ which is attached to the hydroxyl group. The carbon-28 of the carboxyl group was ascertained by the peak at $\delta 179.1$. The analysis of ${ }^{1} \mathrm{H}$ NMR and DEPT-135 spectral data confirmed that the molecule contains six methyl, eleven methylene, six methine and seven quaternary carbons. All the above spectral data analysis suggested that the compound (2) is a pentacyclic triterpenoid containing one hydroxyl, one double bond and a carboxyl group. The following structure of the compound was also confirmed by the fragment ions present in the mass spectral data.

Based on all spectroscopic data, literature values [24] and melting point of the compound, it was confirmed that the compound L4 is betulinic acid. The compound was found from the leaves as well as from the plant $C$. roseus for the first time. The structure of the compound (2) is given below:

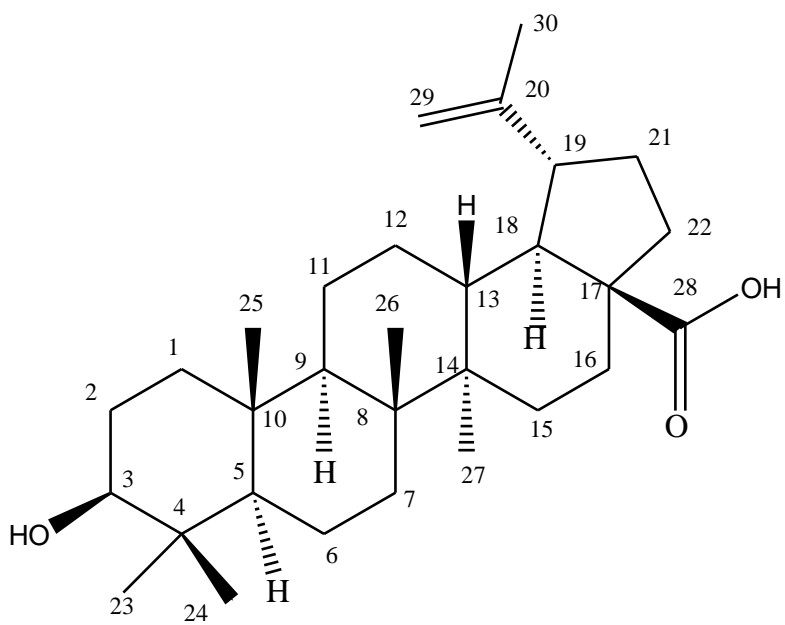

3及-Hydroxy-lup-20 (29)-en-28-oic acid or Betulinic acid (2)

The compound (3) (9.3 mg) was found as white crystals and was completely soluble in the mixture of chloroform and methanol. Melting point of the compound was found as $283-285^{\circ} \mathrm{C}$. It showed single spot on TLC plate with $\mathrm{R}_{\mathrm{f}}$ value 0.65 in $100 \% \mathrm{CHCl}_{3}$.

The mass spectrum of the compound showed a molecular ion peak at $\mathrm{m} / \mathrm{z} 456$ corresponding to the molecular formula $\mathrm{C}_{30} \mathrm{H}_{48} \mathrm{O}_{3}$. The IR spectrum of the compound (3) showed absorption band at $3421 \mathrm{~cm}^{-1}$ due to the $\mathrm{O}-\mathrm{H}$ stretching vibration. It is also supported by 
the absorption bands at 1284 and $1171 \mathrm{~cm}^{-1}$ due to the C-O stretching vibrations. The sharp absorption bands at $2925 \& 2871 \mathrm{~cm}^{-1}$ for saturated C-H stretching vibrations and bands at $1456 \& 1376 \mathrm{~cm}^{-1}$ due to $\mathrm{C}-\mathrm{H}$ bending vibrations, respectively. The presence of $\mathrm{C}=\mathrm{O}$ stretching vibrations was indicated by the absorption band found at $1687 \mathrm{~cm}^{-1}$.

In the ${ }^{1} \mathrm{H}$ NMR spectrum, the one-proton unresolved singlet at $\delta 5.12$ showed the presence of an olefinic proton at $\mathrm{C}-12$ in the molecule. This was supported by peaks at $\delta 138.1 \& 125.4$ in the ${ }^{13} \mathrm{C}$ NMR spectrum which indicated the presence of an olefinic bond. The triplet at $\delta 3.08(1 \mathrm{H}, J=7.2 \mathrm{~Hz})$ clearly showed the presence of $>\mathrm{CHOH}$ group which was further supported by the signal at $\delta 78.8$ in the ${ }^{13} \mathrm{C} N M R$ spectrum indicated the carbon at position- 3 in the structure. The presence of seven methyl groups in the compound was ascertained by the five $3 \mathrm{H}$ singlets at $\delta$ $0.97,0.86,0.80,0.69,0.66$ and two $3 \mathrm{H}$ doublets at $\delta 0.83$ \& 0.75 in the ${ }^{1} \mathrm{H}$ NMR spectrum.

The ${ }^{13} \mathrm{C}$ NMR spectrum of the compound showed 28 signals for 30 carbons. The two intensified peaks at $\delta 38.6 \& 27.9$ obtained due to four carbons. The carbon of carboxyl group (C-28) was indicated by the signal at $\delta$ 180.7. There are seven methyl, nine methylene, seven methine and seven quaternary carbons present in the molecule which was undoubted confirmed by the analysis of ${ }^{1} \mathrm{H}$ NMR, ${ }^{13} \mathrm{C}$ NMR and DEPT-135 spectral data. All the above data analysis suggested that the compound is a pentacyclic triterpenoid containing one hydroxyl group, a carboxyl group and one double bond. Finally, the stucture of the compound (3) was confirmed by the fragment ions at $\mathrm{m} / \mathrm{z} 248$ (base peak) and 203 [248-45 (-COOH)] present in the mass spectrum which are very consistent with the given structure.

Based on all spectroscopic data, literature values [25] and melting point of the compound (3), it was confirmed that the compound is Ursolic acid. The structure $\mathrm{f}$ the compound is given bellow:

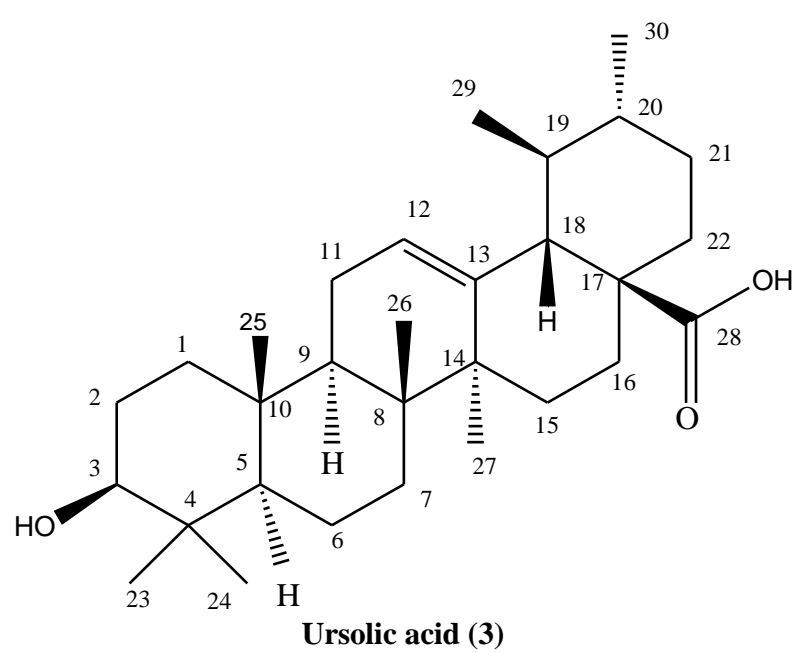

The compound (4) (7.6 mg) was found as yellow crystalline solid and was soluble in methanol. Melting point of the compound was found as 354-356 C. It gave positive test with $\mathrm{FeCl}_{3}$ solution indicated the presence of phenolic hydroxyl group in the molecule. It showed single spot on TLC plate with $\mathrm{R}_{\mathrm{f}}$ value 0.54 in $20 \%$ n-hexane in ethyl acetate. The mass spectrum of the compound (4) showed a molecular ion peak at $\mathrm{m} / \mathrm{z} 318$ which is corresponding to the molecular formula $\mathrm{C}_{15} \mathrm{H}_{10} \mathrm{O}_{8}$. The UV spectrum showed the absorption bands at $\lambda_{\max } 379,320$ and $303 \mathrm{~nm}$ indicated the presence of conjugation with chromophoric groups and suggested a flavonoid skeleton. The bands at 3365 and $1659 \mathrm{~cm}^{-1}$ in the IR spectrum indicated the stretching vibrations of hydroxyl and carboxyl groups, respectively. The lower value of the carbonyl stretching vibrations was due to the presence of conjugation and chelation with hydroxyl group which was also supported by the peak at $\delta 177.3$ in the ${ }^{13} \mathrm{C}$ NMR spectrum.

In ${ }^{1} \mathrm{H}$ NMR spectrum, there were only three peaks available in aromatic region. The two protons singlet at $\delta 7.33$ showed the presence of two equivalent protons attached to C-2' \& C-6'. The two doublets (one proton each) at $\delta 6.36 \& 6.17$ with coupling constant, $J=$ $2.0 \mathrm{~Hz}$ easily confirmed the two meta coupled protons at C-6 \& C-8, respectively. Total thirteen peaks showed by the ${ }^{13} \mathrm{C}$ NMR spectrum for fifteen carbons. Two pairs of equivalent carbons at C-3' \& C-5' and C-2' \& C-6' were easily ascertained by the two intensified peaks at $\delta 146.7$ and 108.5, respectively. Three peaks in the DEPT-135 spectrum for four $=\mathrm{CH}$ - was also supported the given structure of the compound. Finally the fragment ions present in the mass spectrum confirmed the following structure of the compound.Based on all spectroscopic data, literature values[26] ${ }^{\text {[and }}$ melting point of the compound (4), it was confirmed that compound is 3,3',4',5,5',7-hexahydroxy flavone or Myricetin. The compound was found from the leaves as well as from the plant $C$. roseus for the first time. The structure of the compound (4) is given below:<smiles>O=c1c(O)c(-c2cc(O)c(O)c(O)c2O)oc2c(O)c(O)c(O)c(O)c12</smiles>

3,3', $4^{\prime}, 5,5^{\prime}, 7-h e x a h y d r o x y$ flavone or Myricetin (4)

\section{CONCLUSION}

Literature survey showed that very little phytochemical studies have been done on ethyl acetate extract on leaves of the plant Catharanthus roseus. The isolation and characterization of four compounds from 
leaf part of the plant have been reported here. We believe, there is a scope to do more detailed phytochemical and biological study on this plant in future.

\section{ACKNOWLEDGEMENT}

We are grateful to Division in charge, Chemical Research Division, BCSIR Laboratories, Dhaka and Director, BCSIR Laboratories, Dhaka, for providing necessary facilities to carry out this research work.

\section{REFERENCES}

1. Nair LD, Sar SK, Arora A, Mahapatra DA. Comparative study on proximate analysis conducted on medicinal plants of Chhattisgarh, CG, India Research Journal of Chemical Sciences. 2012; 2(9):18-21.

2. Uduak E, Emana A. Proximate Composition and phytochemical constituents of Aspillia Africana (Pers) C.D.Adams \& Tithonia diversifolia (Hemsl) A.Gray Stems (Asteraceae). Indian $\mathbf{J}$ of Pharmaceutical \& Biological Res. 2013; 1(1): 23-30.

3. Sofowora AA. Medicinal Plants and Traditional Medicine in West Africa. Second Edition, John Willey and Sons Ltd. New York, 1993: 289.

4. Ogundare AO. Antimicrobial Effect of Tithonia diversifolia and Jatropha gossypifolia Leaf extracts. Trends in Applied Science and Research. 2007; 2(2):145-150.

5. Jaleel CA, Gopi R, Paneerselvam R. Alterations in non-enzymetic antioxidant components of Catharanthus roseus exposed to paclobutrazol, gibberellic acid and Pseudomonas fluorescens. Plant Omics J. 2009; 2(1):30-40.

6. Huxley A. New RHS Dictionary of Gardening, Macmillan ISBN.1992:0-333-47494-5.

7. Ambusta CS. The Wealth of India. Raw Materials (Revised Edition), Publication and Information Directorate, CSIR, New Delhi, 1992; 3:117.

8. Mishra P, Uniyal GC, Sharma S, Kumar S. Pattern of diversity for morphological and alkaloid yield related traits among the periwinkle Catharanthus roseus accessions collected from in and around Indian Subcontinent. Genetic Res Crop Evol. 2001; 48:273-286.

9. Farnsworth NR, Svoboda GH, Blomster RN. Antiviral activity of selected Catharanthus alkaloids. J. Pharm. Sci. 1968; 57:2174-2175.

10. Gajalakshmi S, Vijayalakshmi S, Devi Rajeswari V. Pharmacological activities of Catharanthus roseus, a prospective review. Int J Pharm Bio Sci. 2013; 4(2):431-439.

11. Forsyth WGC, Simmonds NW. Anthocyanidins of Lochnera rosea. Nature. 1957; 180:247.

12. Nishibe S, Takenaka T, Fujikawa T, Yasukuwa K, Takido M, Morimitsu Y, Hirota A, Kawamura T,
Noro Y. Bioactive compounds from Catharnthus roseus and Vinca minor. Natural medicines (Tokyo). 1995; 50:378-383.

13. Bruneton J. Pharmacognosy: phytochemistry medicinal plants, 2 edn. Intercept Ltd., hampshire, UK, 1999:227-231.

14. Filippini R, Caniato R, Piovan A, Cappelletti EM. Production of anthocyanins by Catharanthus roseus. Fitoterapia, 2003; 74:62-67.

15. Srinivasa RA, Fazil MA. Simultaneous estimation of quercetin and rutin in ethanolic extract of Catharanthus roseus. Linn Leaves by HPLC method, International Global Research Analysis, 2013; 2(7).

16. Atta-Ur-Rahman, Bashir M, Hafeez M, Parveen N, Fatima J. 16-Epi-19-s-vindlinine, an indole alkaloids from C.roseus. planta Med. 1983; 47:246-247.

17. Atta-Ur-Rahman, Fatima J. Isolation and stucture of rosicine from $C$. roseus. Tetrahedron letters 1984; 25(52):6051-6054.

18. Atta-Ur-Rahman, Ali I, Chudhury. Isolation and 13C-NMR studies on cathovaline on alkaloid from leaves of C. roseus. planta Medica. 1985; 5:447-448.

19. Atta-Ur-Rahman, Alam M, Ali I, Habib-ur-Rahman, Huq I. Leurosinone: a new binary indole alkaloid from $C$. roseus "perkin-transaction-I No 8. 1988; 2175-2178.

20. Auriola S, Naaranlahti T, Kostianen R, Lapinjaki SP. Identification of indole alkaloid from $C$. roseus with liquid chromatography/mass spectrophotometry using collision -induced dissociation with thermospary ion repeller' Biomed Environ mass Spectrum, 1990 July; 19(7):400-404.

21. Nikita V, Tayade DT, Rahimullah SU. Studies in the proximate analysis of leaves of Murraya koenigi L. from Amravati belongs to Maharastra state. Int J of Natural Products Research. 2012; 1(3):40-41.

22. Ghias UW, Bina SS, Mohammad A, Anwar S, Asfaq A, Ala U. Chemical constituents and phytotoxicity of solvent extracted fraction of stem bark of Grewia optiva Drummond ex. Burret, Middle -East Jounal of Scientific research, 2011; 8(1):85-91.

23. Enamul H, Hussain US, Akim UM, Hafizur R, Mydul Islam AKM, Sabir Hossin M. Triterpenoids from the stem bark of Avicennia Officinalis". Dhaka Univ J Pharm Sci. 2006; 5(1-2):53-57.

24. Ibrahim T, Babalola, Francis O. Shode Ubiquitous, Ursolic Acid; A potential pentacyclic triterpene natural product. Journal of Pharmacognosy and Phytocemistry. 2013; 2(1):214-222.

25. Jorge M. Flavonol Glycosides from Davilla flexuosa, J Braz Chem Soc. 1996; 7(2):115-11. 